\title{
LOS SONETOS DE ÁNGEL GONZÁLEZ: TRADICIÓN LITERARIA Y EXPERIENCIA
}

\author{
Ángel Luis Luján Atienza \\ Universidad de Castilla-La Mancha
}

La escasa presencia de sonetos en la producción de Ángel González (dieciséis en una obra que abarca más de cinco décadas) es la probable causa de que apenas se haya estudiado este aspecto en la poesía del ovetense. Pero es precisamente la escasez y excepcionalidad en su cultivo lo que quizá hace más significativa la aparición de esta forma, a lo que hay que añadir el hecho de que, si bien la mayoría de los sonetos se agrupan en los inicios de su carrera lírica (los dos primeros libros suman once de los dieciséis totales), González parece haber sentido cierto apego por ellos, pues no deja de cultivarlos hasta el final. De hecho, es el soneto la única forma métrica del repertorio a la que se atiene; a excepción de unas décimas en Áspero mundo, con muchas licencias (Alarcos, 1996: 63), y unos serventesios titulados «Calambur» en Muestra, corregida y aumentada (322) ${ }^{1}$. Tampoco es muy partidario nuestro poeta de la rima consonante, propia del soneto, aunque aprovecha en ocasiones sus potencialidades humorísticas y sarcásticas, cuando no socarronas.

Contribuye también a esta desatención crítica el hecho de que el tono propio del soneto no coincide con lo que acabará siendo el estilo característico de la poesía de Ángel González, apreciable ya desde las primeras entregas, cuando el soneto es todavía un elemento que merece toda una sección del poemario Áspero mundo. Como se la ha venido definiendo, la de Ángel González es una poesía de la ironía, el humor, las formas sueltas, el tono coloquial..., 
rasgos que se compadecen poco con la rigidez y la elevación que prototípicamente se atribuyen al soneto.

El mismo autor ha hecho una distinción, a propósito de su obra primera, entre los poemas de un carácter más personal y los de inspiración más libresca. Sobre los sonetos de Áspero mundo declara:
versos muy literarios que expresaban poco o nada de mí: va- gas disposiciones sentimentales, emociones más inventadas o deseadas que vividas (los Sonetos, casi todas las Canciones, y también los poemas de la parte titulada Acariciado mundo que, aunque derivados de un sentimiento amoroso verda- dero, son únicamente, en el fondo, un puro ejercicio imagi- nativo) (González, 1980: 16-17).

Ángel González encierra en estas palabras la clave interpretativa de la tensión que existe en toda poesía entre lo literario (lo recibido) y lo vivencial, lo cual se pone especialmente de manifiesto en el uso de formas tan rígidas y tan cargadas de historia literaria como el soneto ${ }^{2}$. La tensión se incrementa cuando el poeta que elige el soneto opta, como es nuestro caso, por una poesía de la experiencia personal y de la comunicación inmediata con el lector. Literatura y vida, forma y vivencia son los dos polos entre los que se mueve toda poesía, y el soneto es especialmente apropiado para estudiar esta convivencia conflictiva de elementos, en tanto que tiende a la primacía de la forma y tiene una extensa historia literaria detrás.

\section{UNA LARGA TRADICIÓN}

Escribir sonetos supone adherirse a una larga tradición y continuarla. Es una forma tan cargada de historia que el que decide aventurarse ahí no puede más que remitirse a todas las creaciones anteriores que adoptan esta forma. Componer un soneto es enredarse desde la primera palabra en la madeja intertextual, así que la primera pregunta que nos debemos hacer es cuáles son las influencias concretas de Ángel González en este campo.

Algunas de ellas nos son desveladas por el propio autor. Sometido a la pregunta de "por qué escribo», González contesta:

2 A esta tensión se refiere Alarcos cuando afirma que Ángel González ha rehuido las «normas estróficas tradicionales» porque "[n]o ha querido que un esquema previo torciese el rumbo de su inspiración» (1996: 63). 
Comencé a leer de niño, y los síntomas del contagio se manifestaron precozmente con efectos que no dudo en calificar, apelando a un neologismo que ruego me disculpen, de cataestróficos: a los doce años de edad ya había incurrido en décimas y sonetos cuyos principales causantes (no diré culpables) eran Espronceda y Rubén Darío (2005: 462).

Ángel González usa el término "contagio» para hablar de influencias poéticas (o intertextualidad), un término que se ha acuñado desde la teoría cognitiva de la cultura para explicar cómo se

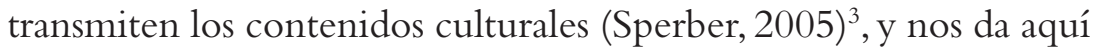
incluso una posible explicación de por qué es tan "contagioso» el soneto: es la forma "estrófica» por antonomasia. En efecto, en el canon de la lírica occidental ocupa un lugar central, si no el central (Polo García, 1974), lo que lo convierte en una forma culturalmente "pegajosa».

Al citar a Espronceda y Rubén Darío lo más seguro es que González no nos esté diciendo que sean ellos sus influencias directas en el soneto. De hecho, no es muy visible la huella de ninguno de ellos en nuestro poeta, y tampoco parecen Darío y Espronceda figuras destacadas en el cultivo del soneto; más bien lo que nos quiere decir González aquí es que se atenía a formas estróficas rígidas por influencia de, entre otros, estos dos autores.

Por la época en que empezaba a formarse Ángel González como poeta había toda una atmósfera sonetística a su alrededor. Sonaban y resonaban todavía los de Gerardo Diego, de quien el grupo de amigos adolescentes en Oviedo «[c]asi nos sabíamos de memoria su Primera Antología» (Lombardero, 2006: 20). Sonetos que tenían de alguna manera su continuidad en la producción «filoclásica» de los poetas oficiales de Garcilaso y Escorial; pero por otra parte, Blas de Otero estaba publicando sonetos de un carácter más desgarrado e inconformista, a los que es de suponer (y quedará constancia en su producción) que Ángel González prestaría más atención que a los anteriores. Los de Otero son descendientes de los sonetos de Miguel Hernández, de los que sabemos que Ángel González tenía conocimiento: «Traía [Luis Landínez] también aires nuevos, nos hablaba de Miguel Hernández — al que, de todos modos, nosotros ya conocíamos por sus sonetos— (ibíd.: 25).

La influencia de Blas de Otero en la producción de González es innegable, y no solo en los sonetos, también se puede apreciar en 
técnicas poéticas como el juego con los encabalgamientos y la resemantización de expresiones hechas e idiomáticas (Alarcos, 1997). No es caprichoso, pues, que cuando nuestro autor plantea un homenaje al bilbaíno, una de las dos partes en que lo divide sea un soneto, y tenga su clave interpretativa en una expresión idiomatizada.

El soneto al que me refiero aparece en el libro Prosemas o menos (400). Su factura no es llamativamente oteriana, aunque aprovecha algunas de las características de la poesía del autor de Ancia que a esta altura ya son dificiles de deslindar de las propias del estilo de González, como la dilogía y la paronomasia: «llama», «vez / ved», «impaciente de paz», "dura / dura», «estatua / estatura»; también vemos las ambivalencias provocadas por el encabalgamiento: en el primer verso, "acaso» puede ser sustantivo en primera instancia y adverbio una vez pasamos al segundo verso.

Todo el soneto se basa en una metonimia por la que Otero aparece como «una voz»; parece que González quisiera centrar la atención del lector en la figura del poeta, en su decir lírico, aunque acaba haciendo un homenaje a la "estatura» humana del hombre al que pertenecía esa voz. De hecho, el soneto acaba con un tópico muy difundido como es el de la perdurabilidad de la palabra poética, hecha monumento, que parte de Horacio (Exegi monumentum aere perennius), está en los sonetos de Shakespeare (Shall I compare thee to a summer's day?) y en "The canonization» de John Donne.

El soneto, pues, plantea (y va a ser una constante) el problema esencial a toda literatura, particularmente a toda literatura que quiera hablar de la vida: el hombre que escribe (en su "estatura» humana) debe hacerse voz, y la voz "estatua», materia inerte encerrada en la estrecha cerca verbal del soneto, mármol de palabras. La paronomasia, en este caso, se pone al servicio de la expresión de esta tensión entre lo rígido y lo vivo.

Para compensar tal fijación y deshumanización González identifica la voz de Otero con fuerzas naturales: la luz, el fuego, el viento, la sangre; pero más importante en este proceso es la estrategia de la autocita, que incluye al propio autor en su poema, y con ello una indicación de que es el hombre Ángel González el que habla al hombre Blas de Otero. Si nos fijamos, la expresión «Era roja esa voz en el ocaso» no puede por menos que recordarnos aquel célebre encabalgamiento de Áspero mundo: «hacia el marzo del viento y de los rojos / horizontes» (16), donde el color deja de ser literario para hacerse ideología, ámbito en el que ambos hombres se 
encuentran en una palabra que más allá de la literatura habla de sus creencias compartidas.

Pero lo más sintomático del poema es cómo juega el poeta con las frases hechas, procedimiento preferido de Otero, y que sitúa el discurso en esa quiebra entre el coloquio diario y la rigidez sonetística.

El primer ejemplo lo encontramos en «sangre que clama / al cielo», un cliché que se ve roto por la expresión coloquial «ese de los hombres, raso». Con ello consigue nuestro autor reunir las dos facetas de la obra de Otero, la metafísica desgarrada y la que baja el cielo a los hombres, es decir, a la altura de sus casas, o en paráfrasis: de tejas abajo.

Nos interesa en especial la siguiente expresión: "como si tal cosa», también dilógica. Por una parte indica la naturalidad, la expresión directa y sin esfuerzo de una parte de la poesía de Otero, como nacida espontáneamente de sí, y, recontextualizada por el paréntesis siguiente: "(alzarse en estos tiempos)», da cuenta de la enorme y arriesgada tarea que cumplió esa voz, su desafí y valentía. Esta doble interpretación demuestra lo que la poesía tiene de contradicción y confluencia entre la naturalidad y el esfuerzo, ingenium y ars (si queremos, en términos tradicionales), y lo significativo es que la clave de la dicotomía se presente en una expresión coloquial: «como si tal cosa». El poeta de pronto complejiza el lenguaje diario para demostrar que en el idioma, por muy gastado que parezca, siempre late la posibilidad de encontrar poesía, que quizá ese esfuerzo de devolver a la lengua diaria un esplendor olvidado es la poesía, y que tal empresa debe ir dirigida a luchar por el hombre.

Recuérdese que Otero practica un juego muy similar con la expresión "como si nada» en el cierre del soneto "Voz en lo negro»: «Y el muerto sigue en él, como si nada / más que nacer hubiese sucedido» (Otero, 2003: 45). El coloquialismo "como si nada» se resemantiza para darnos la idea de que para morir solo es necesario haber nacido o la inmediatez en que se encuentran nacimiento y muerte.

Aparte de este homenaje directo, podemos detectar alguna huella más de la poesía de Otero como estas dos del soneto «Me he quedado sin pulso y sin aliento": "por más que estiro / los brazos como un ciego contra el viento" y "contra todo me doy, ciego me hiero» (40), que constituyen gestos poéticos muy oterianos, o en «Se me hiela la voz en la garganta» (45): «mi voz, ceniza densa, se 
levanta». En ellos se aprecia la densidad sonora y la corporalización de movimientos anímicos, que destaca en el estilo de Otero.

La influencia de Hernández, que a veces es difícil deslindar de su presencia en Otero, está clara en uno de los sonetos primeros: «Alga quisiera ser, alga enredada» $(44)^{4}$, que no puede más que recordarnos el «Fuera menos penado si no fuera» de El rayo que no cesa (Hernández, 1991: 97). Los dos poemas están relacionados por el uso de la figura de la epanadiplosis, más matizada en González, pues a cada sustantivo repetido le sigue un adjetivo y el procedimiento se limita a los dos versos que abren los cuartetos. Ambos textos pertenecen a la larga tradición de los sonetos amorosos, aunque el de Hernández tiene un fondo existencial del que carece el del ovetense. La misma forma, pues, de repetición produce efectos diametralmente opuestos: mientras que en González es una muestra del júbilo por la contemplación de la amada, una manera de poseerla, e indica expansión, incluso desde el punto de vista sintáctico («alga» $\mathrm{y}$ "agua» expanden su significado a partir de su primera aparición), en Hernández la repetición al principio y final de verso indican la clausura, la angustia que produce el rechazo, de una manera más obsesiva al ser más constante la repetición. Además, los elementos repetidos son claramente contrastantes: «alga, agua» en González, «cardo, tuera, zarza...» en Hernández.

El ambiente marino del soneto de González aparece apuntado en "ola tu cuerpo si lo alcanzo, ola», de Hernández, donde esta es símbolo de fugacidad y de frustración mientras que es de estabilidad en González.Tenemos, pues, aquí una lectura positiva y superadora del soneto de Hernández, con un cierre que recuerda al becqueriano «himno gigante y extraño» cantado al oído de la amada.

El inicio del siguiente poema, «Se me hiela la voz en la garganta», es de un arranque también muy hernandiano, como, de hecho, lo son los inicios de casi todos estos sonetos primeros: «Me he quedado sin pulso y sin aliento» (40). Generalizando, podemos decir que la lectura que González hace de Otero y lo que aprovecha de su tono poético (aparte de las influencias técnicas que hemos visto) es la capacidad de convertir los movimientos anímicos en estados corporales, en gestos que suponen violencia o distorsión de las posturas naturales (caída, estiramiento), mientras que de Hernández destaca la sensación de ausencia y de carencia continua

4 Se pueden ver los análisis de este poema que hacen Abad, 1990 y Alarcos, 1996: 127-129. 
y sin remedio. Al poner en paralelo los sonetos «Alga quisiera ser, alga enredada» $\mathrm{y}$ «Fuera menos pesado si no fuera», la plenitud del primero hace resaltar el vacío amoroso y vital del segundo.

En cuanto a las influencias clásicas, aparte de algún caso de conceptismo barroco que se puede asimilar a las dilogías que ya hemos visto, sin duda el más gongorino de los sonetos del corpus es el titulado "Geografia humana» (41), que establece un paralelo entre la belleza del cuerpo de la mujer y los accidentes geográficos del mundo en una sostenida alegoría, con algún hipérbaton de filiación claramente cultista: "meridianos rompiendo en su locura», y un léxico en la misma línea: «Lúbrica polinesia», «pulida mar», «helados círculos polares»... El cordobés trató el mismo tema en el soneto «De pura honestidad templo sagrado» (Góngora, 1985: 118), donde va comparando las partes del cuerpo femenino con las de un templo, pero quizá temáticamente la influencia la reciba nuestro poeta de Neruda: "Cuerpo de mujer, blancas colinas, muslos blancos, / te pareces al mundo en tu actitud de entrega», o incluso de Aleixandre en una versión más cósmica ("Unidad en ella», por ejemplo).

Sin embargo, del Siglo de Oro no es Góngora el preferido por González, como es de suponer.Varios de sus sonetos tienen la andadura más suelta y ágil de muchos de los de Lope, cuya influencia le pueda venir quizá de su reflejo en la poesía de José Hierro, y desde luego porque Lope representa lo más experiencial de la poesía barroca. Por ejemplo, en «Luz llamada día trece» (97) y «Donde pongo la vida pongo el fuego» (128) asistimos a esa flexibilidad, propiciada sobre todo por lo pautado de los versos, que están llenos de pausas internas, lo que nos remite a la famosa definición poética del amor: «Desmayarse, atreverse, estar furioso», aunque es claro que González introduce injertos oterianos en estos poemas que desmontan el tono burlón y juguetón que tenían los versos de Lope: «de mi pasión volcada y sin salida»; a lo que hay que añadir un léxico de la herida, la batalla, la derrota, que lleva la desenvoltura lopesca a terrenos existencialistas.

Otra influencia del Siglo de Oro podemos ver en los sonetos que siguen la tradición barroca de lo burlesco sobre todo en su vertiente de desmitificación, que en el caso de González llega a lo sacrílego en «El Cristo de Velázquez» (que estudiaré después) y que se moderniza en el titulado «Danae» (42).

Este último poema es un buen ejemplo de la continuidad de la práctica desmitificadora, especialmente relevante en una época 
en que lo mítico ya no asoma en el horizonte artístico ni ocupa el centro de lo literario, como ocurría en épocas pasadas. Como mucho lo mítico ha servido en el siglo XX para dar profundidad antropológica a determinadas vivencias modernas (el Ulises de Joyce o el Prometeo de Unamuno, por poner solo dos casos). Sin embargo,Ángel González al optar por lo burlón (más que burlesco) rescata, para sorpresa del lector contemporáneo, una actitud ante la que no sabe muy bien cómo reaccionar.

Contribuye a la suspensión de la interpretación el choque entre la estética delicada del inicio y el demoledor giro final. El soneto comienza en un ambiente decadentista y simbolista, que podía haber sido tomado de Juan Ramón o de algún modernista tardío: «La tarde muere envuelta en su tristeza». El léxico colabora a crear esa atmósfera de desidia casi finisecular: melancolía, belleza, caricia, tarde lenta y rosa. Se cuela incluso algún cultismo de origen gongorino, generando cierto preciosismo fónico: «caricia que la oprime con pereza». La demorada andadura del soneto contribuye a la sensación de desidia. En este cuadro vago y vagamente sensual nada nos hace esperar la crudeza del coloquialismo final, que degrada la molicie en una imagen vulgarmente sexual y nada sensual: «y se deja, pensando en otra cosa».

Esta ruptura sorpresiva abre el soneto a dos interpretaciones. Una nos lleva a compararlo con el famoso cuadro de Tiziano, que es el que puede haber tenido González a la vista y servirle de inspiración, pues la protagonista pictórica también parece «dejarse hacer» por contraste con la avidez que demuestra la vieja al recoger las monedas. Tanto el cuadro como el soneto de González están en la línea del Quevedo que escribe: «Volvióse en bolsa Júpiter severo; / levantóse las faldas la doncella / por recogerle en lluvia de dinero» (Quevedo, 1990: 529). La novedad que aporta González al tema de la mujer que vende su sexualidad por dinero es el ambiente de refinamiento burgués de la estampa, en la que la mujer-Dánae resulta ser una belleza aburrida mantenida por el burgués-sol. La desencantada vida de la protagonista queda encerrada en un soneto como en su cuarto; el "pajarillo» aparecería entonces como elemento de contraste, pues es libre mientras ella vive en una jaula de lujo, pero triste.

Al detectar nuestra lectura una proximidad a cierta estética periclitada (marco perfecto de unas relaciones sexuales que tienen mucho de rancio y claustrofóbico) no podemos dejar de lado la interpretación metapoética, máxime cuando el tema mitológico 
pone en primer término su propia literariedad. En esta interpretación el texto no pretende tanto desmontar un mito o una práctica social, sino cierto tipo de poesía decadente y falsamente refinada. De hecho podría ser una respuesta (no necesariamente consciente) al Gerardo Diego de "El soneto de catorce años», o más probablemente al de "Cuarto de baño», en que el contraste entre el mito de Venus y el ambiente burgués de la estancia doméstica pretende simplemente despertar una sonrisa y un leve aleteo de ironía, pero siempre complaciente con esa forma social de cultura, a lo que González opone un sarcasmo claramente subversivo.

Un caso de intertextualidad fortuita, ya que no pudo haber influencia directa, pero muy significativo porque nos habla de confluencia de propuestas estéticas, lo tenemos en el soneto "Capital de provincia», el menos sonetístico de la serie de Áspero mundo, que nos trae a la memoria inmediatamente un poema de Nicanor Parra, del libro Poemas y antipoemas (1954), contemporáneo casi exacto de Áspero mundo. Se trata de «Hay un día feliz», que retrata, en endecasílabos arromanzados, el mismo ambiente que el soneto de González, con la añoranza y la mirada tierna hacia la pequeña ciudad. El poema comparte con el de González la preferencia por la poesía de la cotidianidad. Se puede decir que Ángel González tiene también sus «poemas y antipoemas» en Áspero mundo, como antes se ha indicado. Comparten, además, ambos la estrategia de mezclar imágenes cotidianas directamente expresadas con otras que, por contraste, remiten a un surrealismo que se acerca al realismo mágico o resulta materia de cuento fantástico. Así podemos poner en paralelo el final del soneto de González y esa ciudad convertida en caballo al que se puede palmear el anca con esta semblanza del padre en el poema de Parra:

Lo reconozco bien, este es el árbol

Que mi padre plantó frente a la puerta

(Ilustre padre que en sus buenos tiempos

Fuera mejor que una ventana abierta).

Yo me atrevo a afirmar que su conducta

Era un trasunto fiel de la Edad Media

Cuando el perro dormía dulcemente

Bajo el ángulo recto de una estrella (Parra, 1998: 60).

En diversas ocasiones se ha señalado la intertextualidad como uno de los rasgos más destacados de la poesía de Ángel González. Acabamos de dar cuenta de ella brevemente (las referencias podrían haberse multiplicado) en lo que atañe a los sonetos y hemos 
empezado a ver cómo el acarreo literario deja paso a una voz personal, que va modelando esa tradición para abrirla a interpretaciones y lecturas nuevas. Comprobaremos a continuación cómo se desarrolla esa persona original en los sonetos.

\section{LITERATURA Y VIDA}

A lo largo de la trayectoria literaria de Ángel González las corrientes estéticas se mueven entre las coordenadas duales de compromiso/evasión y comunicación/conocimiento para desembocar finalmente en la dicotomía que podemos articular como experiencia/ lenguaje (Bagué Quílez, 2006; Cullell, 2010; Díaz de Castro, 2003; Lanz, 2000; Prieto de Paula, 1996). Ángel González ha militado siempre en la parte izquierda (nunca mejor dicho) de estos pares enfrentados, su poesía es básicamente comunicativa, comprometida y experiencial, pero ya hemos avanzado que la práctica del soneto puede generar ciertas tensiones, de maneras diversas resueltas, entre lo literario y lo vivencial. Los sonetos suponen una elección libresca que prima la textura del lenguaje sobre el mensaje, la contemplación puramente estética sobre la comunicación de experiencias y pone en primer plano la poeticidad de la forma, particularmente a partir de la existencia del verso libre:

mentre prima della versificazione libera scrivere un sonetto significava semplicemente adottare una delle forme possibili per la poesia, scrivere un sonetto oggi, regolare o, come più normalmente avviene, irregolare, è sempre un gesto che richiama l'attenzione sulla forma, che la presenta in primo piano como oggeto poetico da prendere in considerazione (Beltrami, 2003: 11).

Son varios los críticos que han detectado esta dicotomía entre un poesía más literaria y otra más coloquial dentro de la obra de Ángel González. María Payeras, por ejemplo, pone en paralelo el soneto «Geografia humana» de Áspero mundo y el poema "Artritis metafisica» de Prosemas o menos para ejemplificar extremos cronológicos que son también estéticos (Payeras Grau, 1990: 41). El mismo González insiste en esa dicotomía que recorre sobre todo sus inicios:

Mi primer libro, Áspero mundo, tiene toda una parte de poemas muy testimoniales, basados en datos biográficos 
concretos, junto con poemas de época anterior, cuando yo no pensaba publicar poesía, poemas poco reveladores de mi personalidad, precisamente porque soy consciente de la impudicia de escribir poesía más o menos lírica. Pensando en lo que podía justificar de alguna manera la publicación de un libro de poemas, escribí e incluí una serie de ellos testimoniales, creyendo que dar testimonio de lo que uno siente, piensa, cree y vive puede tener más interés que un simple divertimento estético (en Alarcos, 1996: 202-203).

Pere Rovira acude a los sonetos de Áspero mundo para constatar la existencia de dos voces en nuestro poeta: una de ellas, más auténtica, que surge del enfrentamiento con la realidad frente a un personaje poético «impersonal hablante de estos textos juveniles» (Rovira, 2006: 59).

El problema que se plantea en toda la poesía de Ángel González es el que destaca de manera más palpable en los sonetos: ¿cómo hacer poesía personal con un lenguaje común y una tradición? Si partimos de la dicotomía establecida por Juan Ramón Jiménez, y seguida por autores como Gamoneda, entre "poesía» y «literatura» (Jiménez, 1982: 81-104), que defiende que la primera es inaprensible y su estado ideal es la pura presencia sin forma, mientras que la segunda es comunicada a través de estrategias literarias y forma parte del sistema de géneros junto a discursos no literarios, está claro que lo que González hace es «literatura», un discurso que pertenece a un género literario y que tiene su fundamento en el lenguaje, que usa como medio de comunicación y no como acceso a una experiencia más allá de toda participación con el lector. Ángel González, de hecho, da un paso más y pretende insertar su discurso poético en un discurso social que establece una posición clara frente a la realidad y que pretende actuar en ella. Entraría de lleno en lo que Neruda llama "poesía impura», poesía en la que «está permitido / fijar carteles, / tirar escombros, hacer aguas» (317). Todo ello está dramáticamente expuesto en el poema "Me falta una palabra» (19), en que la construcción puramente lingüística del poema se ve interrumpida continuamente por los discursos y circunstancias de la realidad en su cara más cruda.

Esta «literatura» que busca, más allá del discurso integrado en el sistema de géneros poéticos, una vía de salida hacia la vida, un contacto auténtico con la realidad y una relación lo más inmediata posible con los lectores, lo que podíamos llamar «literatura-vida», tiene que aprovechar las estructuras recibidas y canonizadas por la 
tradición, cuyo máximo exponente puede ser el soneto, para hacer oír una voz personal. La clave está, como se ha explicado repetidamente, en crear un personaje que no es el propio poeta, pero que se le parece, y que es fácilmente asumible por cualquier hablante (García Montero, 2006). El problema que plantea el soneto para esta estrategia es que crea una barrera de extrañamiento o de alienación entre el poeta y su lector que merma el efecto directo de esta voz del «hombre común». Como hemos visto, el soneto, además, atrae una cantidad de ecos intertextuales que forman un acúmulo de voces diversas entre el locutor poético y su lector, voces que en ocasiones pueden servir para conectar con determinado tipo de público, pero que las más de las veces pueden provocar cierto distanciamiento en el lector.

Vamos a examinar ahora, fuera de la apropiación de la tradición ya vista, cómo esa voz personal, ese personaje cómplice se genera en los sonetos a través de diversas estrategias de escritura, pues se trata en todo caso de un efecto del discurso, en tanto que lo vivencial o lo experiencial no son categorías estéticas ni psicológicas.

Para nuestra indagación conviene empezar por los sonetos metapoéticos. El metasoneto, por decirlo así, tiene una tradición antigua; el ejemplo paradigmático es el de Lope: «Un soneto me manda hacerViolante», y tenemos muestras de ello a lo largo de la historia: en Dante Gabriel Rossetti, «The sonnet»; el soneto que abre la colección de Sonetos espirituales, "Al soneto con mi alma», de Juan Ramón Jiménez; o el «Soneto mío» que inicia Alondra de verdad de Gerardo Diego.

De los de Ángel González cinco de ellos se pueden considerar metapoéticos, empezando por los dos últimos de Áspero mundo. El primero de ellos arranca con una afirmación muy oteriana o hernandiana, según vimos: «Se me hiela la voz en la garganta» (45). El poeta plantea en él el tránsito de un tipo de poesía amorosa a una existencial, los dos ejes temáticos del libro. La isotopía del frío que hace que la poesía «dulce» se transforme en hielo, lo que puede relacionarse con el paso del sentimiento vivo a la rigidez de la forma literaria, tiene su continuidad en la isotopía de la ceniza (que representa la grisura de lo existencial y connota la muerte) como producto de un fuego apagado. Lo interesante del poema, y lo que le da su tono personal, es que la metáfora de la ceniza sirve para cerrar el soneto con una reflexión sobre la comunicación poética. En el terceto final el poeta se dirige a sus lectores para mostrarles su convencimiento de que esa ceniza, al contrario que el hielo que 
hace rígido y aísla todo lo que toca, tiene la capacidad de tiznar a quien se pone en contacto con ella. El soneto, pues, propone una comunicación real con el lector, que se contagia del desaliento del poeta, y lo hace a través de una metáfora muy gráfica, que mancha lo que toca.

El que le sigue y cierra la serie revela su carácter metapoético desde el título: «Soneto a algunos poetas» (46). Aquí la intención es claramente satírica y el blanco parece ser la poesía existencialista y tremendista, la de los poetas cuyas "palabras son oscuras». Prieto de Paula ha relacionado este soneto con el poema posterior de denuncia a los «novísimos», titulado "Oda a los nuevos bardos», para demostrar la continuidad en esta actitud crítica de González contra «quienes, en otras circunstancias, escogen una poetización alejada de las preocupaciones cotidianas e históricas» (Prieto de Paula, 2002: 281). Lo curioso del caso resulta ser que, como acabamos de ver en el soneto justamente anterior, el poeta ha practicado el mismo tipo de poesía que parece denunciar.

Se trate de una autocrítica o no, la clave de la innovación del soneto está de nuevo en los tercetos, en los que este tipo de poesía se compara con una mercancía pregonada en la plaza pública, una mercancía, además, a la que nadie atiende. Más allá de la lectura de que ese tipo de poesía que no trata de la vida real del hombre es superflua e inútil, Ángel González critica la mercantilización del mundo moderno incluso en sus expresiones más espirituales. Todo es cuestión de mercado y esta poesía encima es escasamente vendible. Como vemos se trata, en realidad, de la otra cara del soneto anterior, en que la poesía sí tenía un efecto real en los lectores: los tiznaba.

El soneto «Luz llamada día trece» (97) parte de un supuesto más metalingüístico que metapoético, aunque el desplazamiento semántico que se lleva a cabo al inicio es característico de la poesía de Ángel González, pues las palabras no remiten a sus referentes sino que significan por asociaciones emotivas (amor-espanto; primavera-llanto) o ideológicas (cielo-nada; verdad-hombre). Solo el pan y la madera, como esencialidades, mantienen su estabilidad semántica. El segundo cuarteto hace un guiño al origen de esta «trampa» en el nombrar al parodiar Génesis 1, 5: "y llamó Dios a la luz "día" y a la oscuridad la llamó "noche"», lo que eleva al poeta a ser ese «pequeño dios» que quería Huidobro. Este juego de deslizamientos significativos tiene su continuidad en el engaño del encabalgamiento «ayer fue santo / Tomás», que permite dos 
lecturas, para desembocar en la sorpresa final que supone el propio nombrarse uno mismo, es decir: establecer una identidad; identidad que no puede ser más que metafórica o desplazada, pues en ella el yo se presenta como "pasión fatal» (metonimia) que crece como un árbol (comparación metafórica), fatalidad ya preparada por la fecha aciaga que anuncia el título y un verso del poema «día trece».

Como vemos, la reflexión sobre el lenguaje conduce indefectiblemente al problema de la identidad personal, que puede compartir cualquier lector. En este soneto Ángel González ya ha flexibilizado algunas de las formas por el hecho de establecer un encabalgamiento entre los cuartetos y los tercetos, lo que indica también la voluntad de torcer lo literario en busca de una identidad poética propia, a lo que contribuye la presencia de coloquialismos («madera, eso»; «digamos», «de algo hay que hablar»).

El soneto puede leerse a la vez como una respuesta a la posición de Juan Ramón en «Inteligencia, dame el nombre exacto de las cosas», e incluso a la poesía de Salinas cuando González afirma que la luz del día es más verdadera «que cualquier pronombre».

Dejo para el último lugar los dos sonetos homenaje, metapoéticos por ser sus objetos sendos poetas. El de Blas de Otero ya ha sido comentado arriba y el dedicado a Vicente Aleixandre, «De dos palabras nítidas ahora» (82), compuesto para el homenaje que la revista Ínsula dedicó al poeta del 27 en junio de 1959 (Payeras Grau, 1980: 63), no tiene un interés especial.

Aunque nuestro poeta ha vertido sus ideas sobre la poesía en otros moldes, es sintomático que cinco de los sonetos (más de un cuarto de la producción) sean de tipo metapoético. De esta manera, la propia rigidez de la forma es el campo donde se lucha la batalla por la expresión personal, como hemos visto sobre todo en «Luz llamada día trece» y donde el poeta muestra su victoria al doblegar una estructura tan fija.

El resto de los sonetos podemos dividirlos según los dos grandes temas que recorren la obra de González: lo amoroso y lo existencial.

La fugacidad del tiempo es el tema del primero de la serie, «En este instante, breve y duro instante» (39), un tema cuya herencia barroca se refleja en la expresión un tanto enfática: «entrega palpitante», «destello de un diamante», «elevan espirales», que desemboca en un sintagma de gusto muy barroco: «ruina de la aurora», de insinuado oxímoron y con cierta aliteración. El sabor de época lo dan sobre todo los juegos que produce el encabalgamiento, muy 
oterianos: "cristales / rotos», que nos hace pensar en un principio en algo positivo, "cristal», para indicar después su ruptura (el encabalgamiento es icónico, además), o el encabalgamiento entre los tercetos.

Pero lo más personal del soneto es la sostenida tensión que existe entre el mensaje y la estructura del poema, pues la puntualidad hiriente del instante se dilata a lo largo de catorce densos versos, que no son más que la expansión lingüística y temporal de ese término: «instante». La poesía parece detener el tiempo. La propia forma del soneto se presta poco a la fugacidad y a la idea de evanescencia; presenta, por el contrario, una tendencia a la permanencia y la rotundidad.

Nuevamente comprobamos que en los tercetos nos espera una sorpresa, al descubrir que la reflexión general y muy literaria de la premura del tiempo en realidad está enunciada por lo que afecta al hablante: «que ya lo hube perdido». Es el instante universal hecho propio, el único que el emisor puede vivir. De hecho, hay un inicio de diálogo al final del primer terceto con la insistencia, innecesaria para alguien que habla en solitario: «Sí, en este instante, ahora», que indica la implicación vivencial del lector también en ese momento único, compartido y perdido en conjunto en el acto de leer.

De carácter más sombrío es «Donde pongo la vida pongo el fuego" (128), de un barroco en este caso conceptista, con la isotopía del juego, que recorre todo el poema, rozando la alegoría. La andadura de este soneto es más inquieta, debido a que todos los versos son pausados, lo que produce cierto desasosiego en la lectura, a lo que contribuyen los tajantes paralelismos internos, el énfasis del polisíndeton: «y sigo, y juego», y las repeticiones léxicas obsesivas. De esta manera la antigua idea de la vida del hombre como juego y apuesta se ve tratada de manera personal al hacer de la forma un reflejo perfecto de la compulsión del jugador, que como quien vive y escribe esto confia finalmente en la vida.

Podemos considerar «Capital de provincia» (43) de un existencialismo amable o costumbrista, como corresponde al tono de la «antipoesía», con la que lo hemos relacionado antes. Aunque Cilleruelo afirma que en la composición de este poema "pesaron más influencias librescas y cierta ensoñación que la observación de la realidad» (1990: 62), existe una mirada personal sobre la existencia del hombre en esas pequeñas ciudades que se transmite por medio de un ligero humor basado principalmente en una aceptación de las carencias cargada de ingenuidad: "casi realidad», 
"apenas nido», «semiderruido»; la expresión "a casi todas miro tiernamente» referida a las muchachas no puede menos que despertar nuestra sonrisa, por sus implicaciones; implicaciones magistralmente manejadas también en el adverbio "luego», que abre el segundo cuarteto, que supone a la vez posterioridad temporal y de rango, como si los «hombres de vidas apretadas» fueran secundarios en el paisaje urbano.

Como en otras ocasiones, los tercetos resuelven el soneto con una pasmosa declaración de ingenuidad: "Yo estoy contento», que contrasta con la imagen surrealista, pero a la vez profundamente entrañable, de la pequeña ciudad convertida en caballo al que se le puede palmear en las ancas, surrealismo que viene ya anunciado por la innovadora imagen anterior de las muchachas «cual si estuvieran entre amor sembradas».

«Me he quedado sin pulso y sin aliento» (40) es un poema de ausencia en que se funde lo existencial y lo amoroso, como ocurre en Hernández y Otero. La expresión del verso inicial, el gesto de estirar los brazos para tocar el imposible, la repetición de la palabra "ciego» y la imagen final de golpearse y herirse contra todo van claramente en esa línea, hasta el punto de que nos podemos preguntar, como en muchos sonetos de Otero, si se trata de la ausencia de Dios o de la ausencia de la amada. Quizá el único dato que nos dice que se trata de amor humano es la idea de que la ausencia se siente en el cuerpo. En cualquier caso, la artificiosidad general del lenguaje, con juegos derivativos (sienta, sentimiento, siente) y de contraste ("detrás todo de nada») hacen de él quizá el menos personal de los sonetos.

Por contraste, «Geografia humana» (41), que lo sigue, presenta la parte más juguetona de la poesía amorosa. Como ya hemos visto, el tema no es original, y lo que resulta aquí un tanto desconcertante es el cierre: ¿qué quiere decir el poeta con «que te inclinas»? Creo que Ángel González quiere gastarnos una broma al final precisamente burlándose del tópico que ha elegido como tema: la amada está tan cargada de cosas que al final tiene que vencerse ante tanto peso. La poesía ha cargado a lo largo de la historia tanto las tintas sobre la figura de la mujer, que esta no puede más que sentirse abrumada ante tanto preciosismo volcándosele encima. El mismo elemento de contraste con la tradición representa la "pantorrilla», que aparece en «Alga quisiera ser» (44), una zona femenina poco transitada por la sonetística canónica. 
En Tratado de urbanismo, dentro de la sección llamada «Intermedio de canciones, sonetos y otras músicas», tenemos un díptico amoroso que supone una continuidad con los sonetos que acabo de comentar. De hecho, no estamos seguros, como con «Geografía humana», de hasta qué punto pueden representar una parodia de sí mismos o su tema. El que el nombre de la forma métrica aparezca en ambos títulos es significativo. El «Soneto para cantar una ausencia» (238) contiene algunos elementos característicos de la poesía de González como la paronomasia: «pasan / pesan», expresiones coloquiales ("tu ausencia rompe el hilo de mi historia», ruptura encabalgante de un sintagma hecho «endeble muro / de mis lamentaciones»), pero la hinchazón expresiva de «la ilusoria / esperanza de amarte eternamente» y el alambicado conceptismo final, por el que la ausencia de la amada crea una espacio vacío en el que el poeta queda atrapado, pero que no contiene a la amada, con la expresión ambigua «que no te tienes», no pueden más que apuntar a una suerte de juego o parodia.

Más alambicado es el conceptismo de «Soneto para imaginarte con exactitud» (239). Partiendo de una imagen bastante tópica de la amada que ilumina la sombra y abre luz a su paso con su sonrisa, a la que se añade la imagen más tópica aún del vuelo de palomas, llegamos en los tercetos al casi despropósito de fundir esta desbandada con los pensamientos de la amada; por ese camino desembocamos en el tipo de elogio paradójico que utilizó Bécquer cuando comparaba las ideas en la cabeza de la amada con estrellas perdidas en el universo. La imagen que cierra el primer terceto: «con la luz que devana tu cabeza» se puede referir, en esta línea, a que la amada tiene la cabeza a pájaros o que en su cabeza solo hay devaneos. Como en Bécquer, lo que importa finalmente es la belleza de la mujer, más allá de su catadura intelectual o moral.

Ambos sonetos son buen ejemplo de cómo una poesía que juega a la ironía introduce siempre la posibilidad de una doble (o triple) interpretación por muy serios que nos puedan parecer prima facie los enunciados. Al usar la forma soneto, tan seria ella, el poeta lleva un poco más allá el límite en el que el lector está autorizado a esa doble lectura (seria y paródica), y lo deja en un límite casi indecidible, pero que en cualquier momento puede traspasar, resultando de ello un contraste más acusado entre la rigidez de la forma y la flexibilidad de la interpretación.

Fuera de estas categorías encontramos el único soneto verdaderamente burlesco, casi podemos decir irreverente. Quizá por eso 
ha sido, de todo el corpus, el más comentado y aludido por la crítica (Díaz de Castro, 1990: 40; García de la Concha, 2002: 229; Mainer, 2002: 265; Makris, 1991; Payeras Grau, 1990: 43; Prieto de Paula, 2002: 282; Rovira, 2006: 62). Se trata de «El Cristo de Velázquez» (371), de Prosemas o menos, que contiene algún otro poema irreverente como «Invitación de Cristo». Es un soneto irregular, quizá reflejo de lo original de su tratamiento. El primer verso es un eneasílabo, los tres siguientes son alejandrinos; la rima de los cuartetos cambia y las hay imperfectas: «desganado» / "alzados» y «leves» / "atreve». Estamos, pues, ante el soneto donde González rompe más abiertamente las costuras de la forma para expresar más personalmente no una vivencia sino una actitud, y la actitud transgresora se traslada a la forma para construir un soneto que no es completamente tal.

Parte el poema de una metáfora sorprendente y arriesgada: el Cristo, por su posición con los brazos abiertos, visto como el banderillero a la espera del toro. La desgana inicial del personaje es acorde con el eneasílabo, que parece un verso que se queda a medias, frente a los demás.

El cuarteto da un salto de nivel y se centra en el acto de pintar. Con cierto recuerdo rubeniano: «lavó con leves», ahora es el pintor el que se nos presenta bajo la forma de un médico o enfermero de la plaza, que cura la herida del banderillero, no sin cierta sorna presente en el hipérbaton: «a florecer sobre tu piel se atreve».Ángel González consigue un efecto extraño gracias al contraste entre la delicadeza de este cuarteto y el resto del poema.

En el terceto, el «derrote de Dios» del verso 4, término taurino y de resonancias oterianas, se convierte finalmente en la «derrota» a la que sonaba por paronomasia, y el cuidado del pintor no ha sido bastante para salvar la vida del desafortunado banderillero. Finalmente la vida de Cristo se presenta como «aventura absurda, bella y triste», y el cierre epifonemático incluye un elemento dialógico al hacer que intervenga el coro de los aficionados, con la epanadiplosis taurina que recuerda al famoso "6 toros 6", y que resemantiza la expresión «Dios mío», lo que hace que la interjección se convierta a la vez en una invocación, poniendo en solfa el lenguaje corriente.

Es premeditado que González asocie el Cristo a la fiesta taurina, pues aúna así dos símbolos de la España más racial, a la que se enfrenta: la religión y la fiesta de los toros, además de hacer saltar la idea de "sacrificio", al comparar la corrida taurina con una misa. 
Nos servirá para aventurar algunas conclusiones el último soneto regular, este sí canónico, de Nada grave, titulado «Todo el mundo lo sabe» (González, 2008: 65), para mi gusto el mejor de ellos. Creo que en él se compendia todo lo que hemos venido diciendo, pues está cuajado de intertextualidad y contiene a la vez uno de los mensajes más personales del poeta.

El título recuerda el coloquialismo que ha caracterizado toda su obra, y el arranque no puede ser más de su estilo con la disemia y la rima interna: «De tarde en tarde el cielo está que arde». El poeta logra de esta manera renovar el viejo tópico simbolista del atardecer, que es también el de la vida, visto como una hoguera («Las ascuas de un crepúsculo morado», al fondo) quitándole su gravedad, haciendo cómplice al lector, al que guiña el ojo de la tradición.

Las siguientes dilogías: «la luz declina rosa/rosae» y «la fuente conjuga» pueden entenderse como autocita, pues nos remiten inmediatamente al poema «Empleo de la nostalgia» (269), con lo que vemos que el balance de la tarde es también un balance personal y de su obra, a lo que se suma el juego del encabalgamiento, al dejar «conjugar» pendiente de su objeto, que gracias a ello resulta ser doble: el presente verbal es el presente cronológico y existencial del atardecer; vida y lenguaje no pueden más que ir fundidos, existir es ir conjugando tiempos verbales.

La presencia de la fuente que "murmura el cuento claro» nos traslada de nuevo a un paisaje simbolista machadiano, en concreto al de la fuente de "Yo escucho los cantos», que «seguía su cuento», y cuya agua se compara con el canto de los niños, que llevan «confusa la historia / y clara la pena» (1991: 93-94) se complica con una referencia claramente barroca, en la línea de la desazón existencial presente en ambas estéticas: «el mañana y el ayer» del silencio de la tarde no puede más que contener ecos del quevediano «En el hoy y mañana y ayer, junto» del soneto "Ah de la vida», por no hablar de la alusión al nietzscheano mito del eterno retorno de «Todo lo que ya fue volverá a ser», reminiscencia a la vez del Eclesiastés.

5 Sobre la influencia de Machado en Ángel González véase el trabajo de Iravedra Valea (2000). 
El inicio de los tercetos quiebra la trascendencia alcanzada con otro caso de resemantización por énfasis al romper una tautología: el «cuento» de la fuente lo es solo en el sentido peyorativo, un puro artificio literario inventado por modernistas y existencialistas de toda laya. El poeta no se toma en serio ni su propia intertextualidad.

Aquí quiero hacer un inciso para llamar la atención sobre una constante en la construcción de los sonetos que hemos ido comprobando a lo largo de la exposición: la existencia de un punto de inflexión o una resolución sorpresiva en los tercetos (incluso cuando existe encabalgamiento interestrófico) que aprovecha la clara estructura contrastante entre cuartetos y tercetos, y que según Boyd otorga su magia a esta forma:

In the form of the sonnet that Petrarch favored, the fourteen lines divide into an octave, eight lines rhyming abbaabba, and then, usually after a volta - a turn of direction, a change in the movement of thought - a sestet, six lines with a pattern like $c d e c d e$.After first setting up expectations based on patterns of two, the sonnet shifts to a pattern of three, $c d e$, just at the point where the vector of thought also usually veers. The switch of patterns, the momentary instability then recovered from by a different kind of pattern, makes the sonnet's magic (Boyd, 2012: 33).

A ello creo que hace referencia también Alarcos cuando afirma de los sonetos:

La sustancia del contenido en estos poemas es muy concreta, está muy bien delimitada — pudiera decirse- en superficie y cabría resumirla en lo que se llamaría «definición final» de los últimos versos. Lo que les antecede es como variación expresiva de la misma sustancia con objeto de que la «definición final» sea más contundente y produzca más efecto (1996: 63).

Una vez desarmada toda la tramoya literaria de los tópicos utilizados, González nos enfrenta con la realidad cruda, pero para expresar esta superación de lo literario no tiene más remedio que acudir de nuevo a la metáfora: el cielo no arde sino que quema la luz, si bien es verdad que la nueva metáfora nos enfrenta a una realidad más violenta y terminante que la anterior. Estaríamos ante una correctio de la metáfora, pero sin salir de la tradición literaria, pues ahora acuden el tópico del memento homo y una nueva cita barroca, esta vez de Góngora: «humo, ceniza, lejanía» nos remiten sin remedio al final del soneto «Mientras por competir con tu cabello». 
Los dos versos finales, contundentes en su esticomitia y con la ligera irregularidad de la rima (no es acostumbrado hacer rimar dos versos seguidos en los tercetos) nos hacen pensar por una parte en el cierre del ciclo sonetístico en círculo como una vuelta al origen, pues «Esto es lo que nos queda de aquel día» remite por sugerencia a la "primera ruina de la aurora» del soneto inicial «En este instante, duro y breve instante», con el que comparte tema; y por otra parte introducen una alusión literaria al cierre del famoso soneto de Lope: "Esto es amor, quien lo probó lo sabe», donde se puede haber inspirado también el título, que ahora resulta paradójico, pues no todo el mundo parecía saber la verdad aquí expresada.

La aparición sorpresiva, como en muchas otras ocasiones, de un pronombre personal al cierre, en este caso «nos», sirve principalmente para introducir al lector en el soneto; la reflexión general anterior se personaliza y ahora sí todo el mundo debe saber el mensaje de la caducidad de la vida, que dura ese día simbólico. El viento, final depositario de la respuesta, remite, de una manera juguetona, por una parte a Dylan (Bob): «The answer, my friend, is blowing in the wind», y por otra a la tradición literaria y filosófica de la palabra como flatus vocis: todo lo vivido, como todo lo literario, es solo una voz de viento, palabras sin sentido (de nuevo el Eclesiastés).

Este emblemático soneto, que constituye, como se acaba de ver, un balance vital y literario de Ángel González es, además, donde se hacen visibles la mayor parte de las constantes que hemos venido apuntando: intertextualidad, autocita, juegos disémicos, resemantización, encabalgamientos que obligan a reinterpretar expresiones; constantes que se extienden a toda la poesía del autor, pero que acumuladas en el estrecho marco del soneto dan lo peculiar de su uso y lo que de él parece resultar atractivo para el autor: en el soneto da rienda suelta González a un cierto grado de barroquismo, ausente en otros poemas, y aprovecha lo cerrado de la forma para, al forzar, sin llegar a romper completamente, las restricciones de todo tipo (métricas, estructurales, de tono), multiplicar las interpretaciones y los efectos en el lector. Hacer experiencia del soneto es ganar la batalla de la literatura para la vida. 


\section{BIBLIOGRAFÍA}

AbAd, Francisco (1990). «Crítica literaria y lengua poética de Ángel González», Anthropos [«Ángel González. Una poética de la experiencia y la cotidianidad»], 109, pp. 55-59.

Alarcos, Emilio (1996). La poesía de Ángel González, Oviedo, Nobel.

- (1997). Blas de Otero, Oviedo, Nobel.

Bagué Quílez, Luis (2006). Poesía en pie de paz: modos del compromiso hacia el tercer milenio, Valencia, Pre-Textos.

Beltrami, Pietro G. (2003). «Appunti sul sonetto come problema nella poesia e negli studi recenti», Rhythmyca, 1, pp. 7-35.

Boyd, Brian (2012). Why Lyrics Last: Evolution, Cognition, and Shakespeare's Sonnets, Cambridge, MA, Harvard University Press.

Cilleruelo, José Ángel (1990). «Dimensión de la ciudad en la poesía de Ángel González», Anthropos ["Ángel González. Una poética de la experiencia y la cotidianidad»], 109, pp. 60-63.

Cullell, Diana (2010). La poesía de la experiencia española. De finales del siglo XX al XXI, Madrid, Devenir.

Díaz de Castro, Francisco (1990). «Lectura de Prosemas o menos», Anthropos [«Ángel González. Una poética de la experiencia y la cotidianidad»], 109, pp. 44-51.

- (2003). La otra sentimentalidad. Estudio y antología, Sevilla, Fundación José Manuel Lara.

García de la Concha,Víctor (2002). «Segundo tiempo: de Breves acotaciones a Prosemas», Litoral [“Ángel González. Tiempo inseguro»], ed. Susana Rivera, 233, pp. 224-229.

García Montero, Luis (2006). «Historia y experiencia en la poesía de Ángel González», en Ángel González, un clásico de nuestro tiempo, coords. José Guerrero, Elena Peregrina y Álvaro Salvador, Almería, Universidad, pp. 27-40.

Góngora, Luis de (1985). Sonetos completos, ed. Biruté Ciplijauskaité, Madrid, Castalia. GonzÁlez, Ángel (1980). Poemas, Madrid, Cátedra.

- (2005). La poesía y sus circunstancias, ed. José Luis García Martín, Barcelona, Seix Barral.

- (2008). Nada grave, Madrid,Visor.

- (2010). Palabra sobre palabra, Barcelona, Seix Barral.

Hernández, Miguel (1991). El rayo que no cesa, ed. Juan Cano Ballesta, Madrid, Espasa Calpe. 
Iravedra Valea, Araceli (2000). «La presencia de Antonio Machado en el grupo poético de los 50:Ángel González», en Homenaje a José María Martínez

Cachero II: investigación y crítica, Oviedo, Universidad, pp. 839-858.

Jiménez, Juan Ramón (1982). Política poética, Madrid, Alianza.

LANZ, Juan José (2000). Introducción al estudio de la generación poética española de 1968: elementos para la elaboración de un marco histórico-crítico en el período 1962-1977, Bilbao, Universidad del País Vasco.

Lombardero, Manuel (2006). «Memoria de Ángel González», en Ángel González, un clásico de nuestro tiempo, coords. José Guerrero, Elena Peregrina y Álvaro Salvador, Almería, Universidad, pp. 13-26.

Machado, Antonio (1991). Poesías completas, ed. Manuel Alvar, Madrid, Espasa Calpe.

Mainer, José-Carlos (2002). «Variaciones sobre Lázaro, el resucitado, insistiendo en Ángel González», Litoral [«Ángel González. Tiempo inseguro»], ed. Susana Rivera, 233, pp. 260-266.

Makris, M. (1991). «Intertextualidad, discurso y ekfrasis en "El Cristo de

Velázquez” de Ángel González», en Homenaje a Ángel González: ensayos, entrevistas y poemas, eds. Andrew P. Debicki and Sharon Keefe Ugalde, Boulder, Colorado, Society of Spanish and Spanish American Studies, pp. 73-83.

Otero, Blas de (2003). Ancia, Madrid,Visor.

Parra, Nicanor (1998). Poemas y antipoemas, ed. René Costa, Madrid, Cátedra.

Payeras Grau, María (1980). «La poética de Ángel González», Mayurqa: Revista del Departament de Ciències Històriques i Teoria de les Arts, 19, pp. 57-78.

— (1990). «Ángel González: un espíritu burlón», Anthropos [«Ángel González.

Una poética de la experiencia y la cotidianidad»], 109, pp. 35-44.

Polo García,Victorino (1974). «Organización y estructura del soneto como forma poética», Prohemio, 5, pp. 43-61.

Prieto de Paula, Ángel L. (1996). Musa del 68: claves de una generación poética, Madrid, Hiperión.

— (2002). «Ángel González, la fuerza del desaliento», Litoral ["Ángel

González. Tiempo inseguro»], ed. Susana Rivera, 233, pp. 278-283.

Quevedo, Francisco de (1990). Poesía original completa, ed. José Manuel Blecua, Barcelona, Planeta.

Rovira, Pere (2006). «Los prosemas de Ángel González», en Ángel González, un clásico de nuestro tiempo, coords. José Guerrero, Elena Peregrina y Álvaro Salvador, Almería, Universidad, pp. 59-64.

SPERber, Dan (2005). Explicar la cultura: un enfoque naturalista, Madrid, Morata. 